(C) Elsevier/North-Holland Biomedical Press

\title{
INDUCTION OF ANALGESIA BY CENTRAL ADMINISTRATION OF ORG 2766, AN ANALOG OF $\mathrm{ACTH}_{4-9}$
}

\author{
J. MICHAEL WALKER *, GARY G. BERNTSON, CURT A. SANDMAN, ABBA J. KASTIN and HUDA AKIL \\ Department of Psychology, Ohio State University, Columbus, Ohio 43210, Tulane University School of Medicine \\ and Veterans Administration Hospital, New Orleans, Louisiana 70112 and Mental Health Research Institute, \\ University of Michigan, Ann Arbor, Michigan 48109, U.S.A.
}

Received 31 March 1980, revised MS received 23 July 1980, accepted 13 October 1980

J.M. WALKER, G.G. BERNTSON, C.A. SANDMAN, A.J. KASTIN and H. AKIL, Induction of analgesia by central administration of $O R G$ 2766, an analog of $A C T H_{4-9}$, European J. Pharmacol. 69 (1981) 71-79.

Dose-dependent analgesia was produced by microinjection of ORG 2766 into the periaqueductal gray (PAG). This analgesia was found to be potent and long-lasting and occurred at doses which were equimolar to those necessary for morphine analgesia. The same doses failed to produce analgesia by the cerebroventricular route, suggesting that the PAG was the site of action of this effect. Naloxone failed to reduce the analgesia and morphine tolerance did not diminish the effect significantly. Additionally, ORG 2766 at concentrations up to $10 \mu \mathrm{M}$ failed to inhibit binding of $\left[{ }^{3} \mathrm{H}\right]$ naloxone to brain opiate receptors in vitro. These results suggest a non-opiate mechanism of action and are discussed in terms of a proposed $\alpha-\mathrm{MSH}$ or ACTH receptor.

ORG $2766 \quad \alpha$-MSH ACTH Endorphins Pain Analgesia Morphine tolerance

\section{Introduction}

The finding that adrenocorticotropin $(\mathrm{ACTH})$ and $\beta$-endorphin ( $\beta$-END) coexist within arcuate nucleus and pituitary cells (Mains et al., 1977; Watson et al., 1978) and that both are derived from a larger neuronal glycoprotein of 31000 daltons (Roberts and Herbert 1977; Nakanishi et al., 1979) raises new questions about the physiology of these substances. For example, assuming that these polypeptides are released together, it may be asked whether they exhibit antagonistic or cooperative effects. Several interactions between opiates and peptides related to ACTH have been reported in recent years (Wiegant et al., 1977). $\mathrm{ACTH}_{1-24}$ binds

\footnotetext{
* Address all correspondence to J.M. Walker, Mental Health Research Institute, University of Michigan, Ann Arbor, Michigan 48109, U.S.A.
}

weakly to opiate receptors (Terenius et al., 1975; Akil et al., 1980) and produces some naloxone reversable effects after central administration (Gispen et al., 1977). After peripheral administration, ACTH fragments and $\alpha-\mathrm{MSH}$ have sometimes antagonized the effects of opiates (Terenius, 1976; Zimmerman and Krivoy, 1973; Gispen et al., 1975). It has also been suggested that ACTH plays a role in opiate withdrawal (Jaquet, 1978), in addition to a variety of other effects (Kastin et al., 1976; De Wied, 1977; Kastin et al., 1979).

Since ACTH-like peptides may share target cells with opiates, the present experiments were aimed at assessing the effects of an $\mathrm{ACTH}_{4-9}$ analog on a response with known opiate involvement, pain sensitivity. Microinjections into the periaqueductal gray were used because this area is known to be critical to the action of opiates, rich in endogenous 
opiates, and a terminal field for $\mathrm{ACTH} / \beta$ END-containing neurons (Elde et al., 1976; Watson et al., 1977; Yaksh et al., 1976). We now report the induction of analgesia by the $\mathrm{ACTH}_{4-9}$ analog, ORG 2766. This analgesia is highly dose-dependent and occurs at doses which are the molar equivalent to those necessary for morphine analgesia. The analgesia is not reversed by the opiate antagonist naloxone, which may not be surprising since $O R G$ 2766 was found not to exhibit cross-tolerance with morphine and not to bind to opiate receptors.

\section{Materials and methods}

\subsection{Surgical procedures}

At least one week before testing, cannulae were implanted either in the lateral ventricle or the periaqueductal gray. Ventricular cannulae were constructed from 22 ga thinwall stainless steel hypodermic tubing which were sharpened and beveled at the tips. A microsyringe equipped with a 26 ga needle was used for injections. The needle extended $0.5 \mathrm{~mm}$ beyond the tip of the cannula. Ventricular injections were conducted over a period of one minute in a volume of $10 \mu \mathrm{l}$.

Under sodium pentobarbitol anesthesia, ventricular cannulae were placed $1 \mathrm{~mm}$ posterior to bregma, $1.5 \mathrm{~mm}$ lateral to the midline, and $4.1 \mathrm{~mm}$ below the skull surface (lambda and bregma at same DV). Dental acrylic and stainless steel hooks were used to secure the cannula.

Cannulae aimed at the periaqueductal gray were implanted using similar procedures. Cannulae were constructed from 24 ga thinwall tubing. A 31 ga injection needle, which extended $2 \mathrm{~mm}$ beyond the tip of the cannulae was used to avoid unnecessary tissue damage. Using the stereotaxic atlas of De Groot (1959) the cannulae were implanted $0.6 \mathrm{~mm} \mathrm{AP} ; 1.5 \mathrm{~mm} \mathrm{DV}$, and $0.5 \mathrm{~mm} \mathrm{LAT}$. Peptides were delivered in a $2 \mu \mathrm{l}$ volume.

\subsection{Analgesia testing}

Analgesia was measured by the tail-flick test of D'Amour and Smith (1941). The apparatus consisted of an adjustable heat source which could be directed onto the rat's tail. The application of power to the heat source started a solid state latency timer which in turn was stopped by withdrawal of the tail, allowing the light from the heat source to activate a photocell. A digital readout, to tenths of a second, was thus provided for the latency to tail-withdrawal, which is the index of pain responsiveness.

Ninety to 120 day old male SpragueDawley rats were used in all experiments. Eight animals with cannulae in the ventricles and eight with cannulae in the periaqueductal gray were tested once with $3,9.5$ and $30 \mu \mathrm{g}$ of ORG $2766\left(\mathrm{Met}_{[} \mathrm{O}^{2}\right]^{4}, \mathrm{D}-\mathrm{Lys}^{8}$, $\mathrm{Phe}^{9}$. $\left.\mathrm{ACTH}_{4-9}\right)$ and once with Ringer solution. All tests were separated by $48 \mathrm{~h}$ and the order of administration of the various doses was counterbalanced using a Latin Square Design. The central gray group was given an additional test with $30 \mu \mathrm{g}$ of ORG 2766 , in combination with naloxone $(2 \mathrm{mg} / \mathrm{kg}$, administered subcutaneously).

Before testing, the output of the heat source was adjusted to obtain tail-withdrawal latencies between 2.5 and 4 sec. Tail-flick latencies were then measured every 2 min for a baseline period of $15 \mathrm{~min}$. The peptide or control solution was then administered, and testing continued, at $2 \mathrm{~min}$ intervals, for a minimum of $20 \mathrm{~min}$ or until tail-flick latencies had returned to within $30 \%$ of their baseline values on three consecutive trials. In tests of naloxone, baselines were established over 5 trials, followed by microinjection of $30 \mu \mathrm{g}$ ORG 2766. After analgesia was observed, judged by a $30 \%$ or higher increase in tail-flick latency for two tests, $2 \mathrm{mg} / \mathrm{kg}$ naloxone $\mathrm{HCl}$ in saline was injected subcutaneously. Tailflick testing continued for a minimum of 20 $\mathrm{min}$ and then ceased if latencies had returned to within $30 \%$ of baseline values. 


\subsection{Induction of morphine tolerance and its effect on analgesia produced by ORG 2766}

Ten animals underwent surgery as above. The seven which showed the greatest analgesia in response to a pretest with $30 \mu \mathrm{g}$ of ORG 2766 were subjected to further tests to determine whether the analgesia exhibited crosstolerance to morphine. After the initial test with the ACTH analog, the animals were given one test with $10 \mathrm{mg} / \mathrm{kg}$ morphine sulfate (intraperitoneally). Morphine tolerance was then induced by subcutaneous implantation of a morphine pellet (72 $\mathrm{mg}$ ) under light ether anesthesia, followed three days later by the implantation of a second pellet. Four days later $10 \mathrm{mg} / \mathrm{kg}$ morphine was injected again and the resulting analgesic response was measured. Forty-eight $\mathrm{h}$ later the effects of $30 \mu \mathrm{g}$ ORG 2766 was retested. Thus, the analgesic effects of both morphine and the $\mathrm{ACTH}_{4-9}$ analog were observed before and after the induction of morphine tolerance.

Testing for analgesia was as described above for ORG 2766. For morphine, testing ensued 15 min after injection and 5 tests were made at 3 min intervals.

\subsection{Histology}

After behavioral experiments were completed animals were sacrificed by an overdose of sodium pentobarbitol. Brains were fixed by the perfusion of $10 \%$ formalin in saline through the heart. For ventricular placements the brain was cut with a scalpel and the ventricular system was checked for the presence of dye $(0.19 \%$ Evans blue, filtered) which was injected prior to sacrifice. Fifty $\mu \mathrm{m}$ frozen sections were obtained from brains with PAG implants and placements were determined with the aid of the stereotaxic atlas of De Groot (1959).

\subsection{Opiate binding assay}

The ability of ORG 2766 to inhibit the binding of $\left[{ }^{3} \mathrm{H}\right]$ naloxone to opiate receptors was carried out using methods described by Akil et al. (1978). Briefly, whole brain minus cerebellum was homogenized in $10 \mathrm{vol}$ of ice cold $0.5 \mathrm{M}$ Tris- $\mathrm{HCl}$ buffer, $\mathrm{pH} 7.4\left(0^{\circ} \mathrm{C}\right)$ and centrifuged at $35000 \times \mathrm{g}$ for $30 \mathrm{~min}$. After resuspension in the original volume, the preparation was incubated at room temperature for $30 \mathrm{~min}$ and spun again as before. The pellet was again resuspended in the original volume and the assay carried out with $0.5 \mathrm{ml}$ aliquots of this preparation. Labelled naloxone $(3 \mathrm{nM})$ was added to the membrane preparation and incubated for $2 \mathrm{~h}$ at $0^{\circ} \mathrm{C}$ in the presence and absence of $10 \mathrm{nM}$ to $10 \mu \mathrm{M}$ ORG 2766. The assay was conducted in triplicate. Samples were filtered by vacuum over Whatman GF/B filters. The filters were then counted by scintillation spectrometry.

\subsection{Materials}

$\left[{ }^{3} \mathrm{H}\right]$ Naloxone was purchased from New England Nuclear. Morphine Sulfate was purchased from Mallinkrodt. ORG 2766 was a gift from Organon. Naloxone $\mathrm{HCl}$ was a gift from Endo Laboratories.

\section{Results}

\subsection{Histology}

As shown in fig. 1, most of the cannulae were placed in the ventral and lateral portions of the central gray. The only animal who did not show any analgesia after the drug, was also the only animal with a cannula clearly outside the central gray. This data may provide some support for the conclusion that the central gray was the site of action of ORG 2766 in the present experiments.

Dye was injected into the cannulae of animals with ventricular implants. The dye was observed in the lateral ventricles of all animals. Minimal leakage of the drug up the side of the cannula was suggested by the lack of dye on the cortex in all but one animal. For the morphine-tolerant animals, most were 


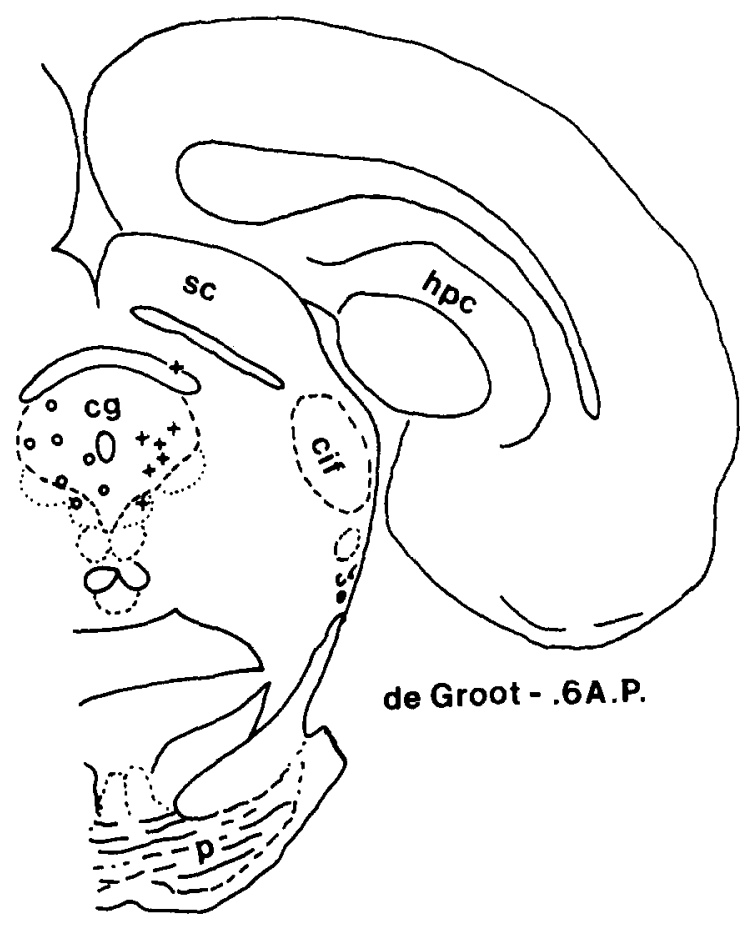

Fig. 1. Microinjection sites for ORG 2766. +, Doseresponse study for one subject (histology lost for one subject). 0 , Cross-tolerance study for one subject.

again found to have cannulae in or very near the central gray. Evans blue was detected in the periaqueductal gray of all rats. Spreading was generally limited to a $1-3 \mathrm{~mm}$ region (see fig. 1).

The effects of various doses of ORG 2766 on analgesia were analyzed by methods described previously (Coy et al., 1978). An overall estimate containing both magnitude and duration of the drug was obtained by subtracting the animals' mean baseline score from each post-injection latency (all animals were included in the analysis). The area under the curve of the resulting time function was estimated using the approximation of Simpson (c.f. Selby, 1964). This conservative method eliminates the inherent problems of analysis of variance with unequal cell sizes (number of tests per session). Moreover, it reduces the effects of the 10-sec ceiling on response latency, which would otherwise severely distort the within subjects variance. Thus, the transformed data for central gray injections were subjected to an 8 (subject) $\times 4$ (dose) repeated measures analysis of variance.

The results of increasing doses of ORG 2766 (in PAG) on tail-flick latency are shown in fig. 2 . One way analysis of variance confirmed the obvious effectiveness of dose $\left(F_{3,21}=10.4, P<0.0001\right)$. No effect of order of test was observed $(F<1)$. Post hoc analysis of individual doses was conducted using the Dunnett test. A significant effect of the $30 \mu \mathrm{g}$ dose compared to the control was observed $(P<0.01)$. The middle dose was not significant but the obvious effects seen in 3 out of 8 subjects strongly suggested that it could indeed induce analgesia.

Analysis of the effects of ventricular injections of ORG 2766 revealed no significant effect of dose for data transformed as above $\left(F_{3,21}=1.29, \quad P=0.30\right)$. These results are illustrated in fig. 3 .

The transformed data of both experiments were combined in a 2 (groups) $\times 8$ (subjects) $\times 4$ (doses) analysis of variance. The large difference between injections into the central gray compared to injections into the lateral ventricle was confirmed by a significant difference between groups $\left(\mathrm{F}_{1,14}=8.23\right.$, $\mathrm{P}=0.01$ ). A main effect for dose was also obviously related to the strong effects of ORG 2766 after central gray injections $\left(\mathrm{F}_{3,42}=9.12, \mathrm{P}<0.0001\right)$.

\subsection{Naloxone effects}

No significant effect was observed for naloxone on analgesia of ORG 2766. Previous investigations with various known narcotics showed that naloxone totally eliminated all signs of analgesia within ten min after injection. In the present experiments the duration of analgesia was defined, as in a previous report (Walker et al., 1977a), as the time during response elevations were $30 \%$ greater than baseline. The duration of analgesia was not affected significantly by naloxone $(\mathrm{T}=0.38$, $\mathrm{df}=5$ ). Duration of analgesia after naloxone 


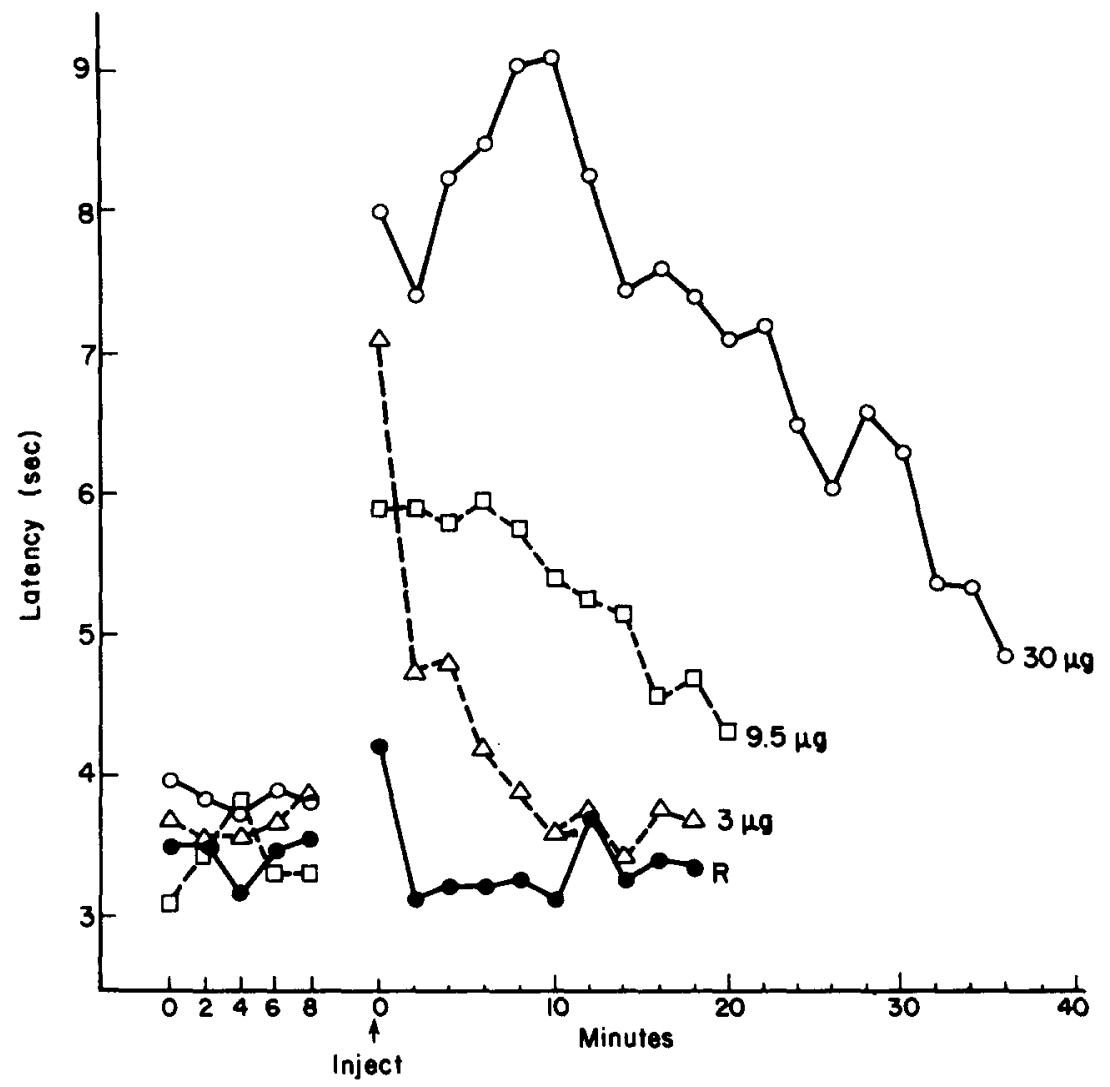

Fig. 2. Mean latency to tail withdrawal from radiant heat before and after microinjection of various doses of ORG 2766 into the midbrain central gray. The peptide was dissolved in Ringer solution and injected in a $2 \mu l$ volume.

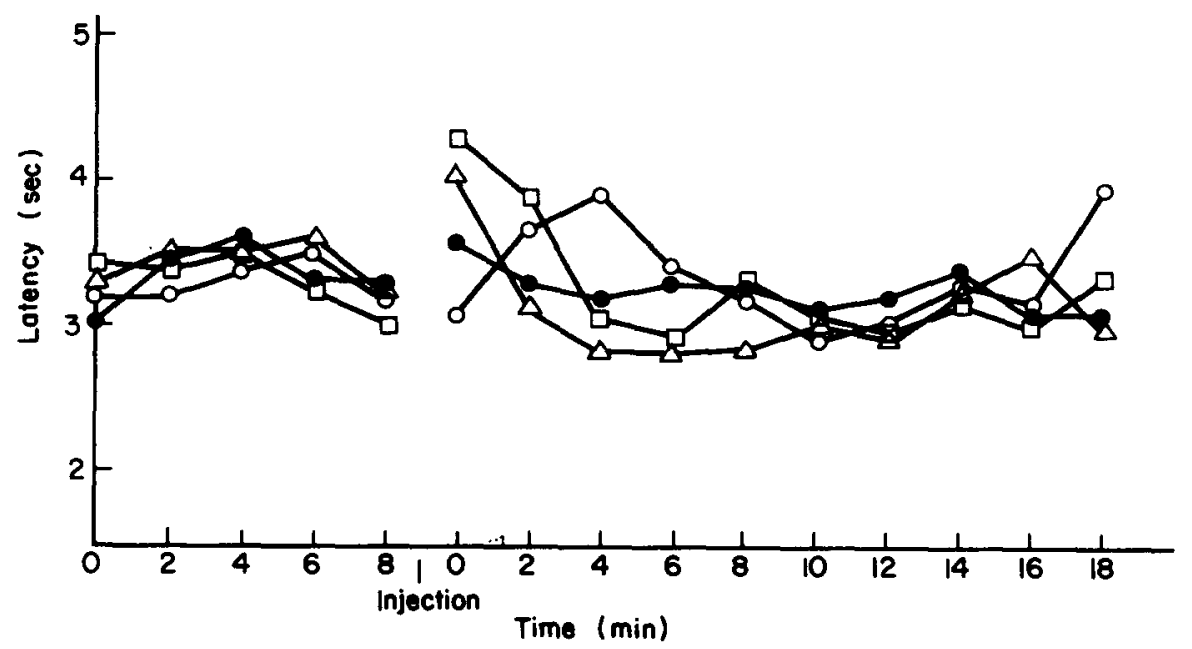

Fig. 3. Tail flick latency before and after lateral ventricular injection of ORG 2766. No significant change in tailflick latency was found for any dose. $O, R ; \bullet, 3 \mu \mathrm{g} ; \square, 9.5 \mu \mathrm{g} ; \triangle, 30 \mu \mathrm{g}$. 


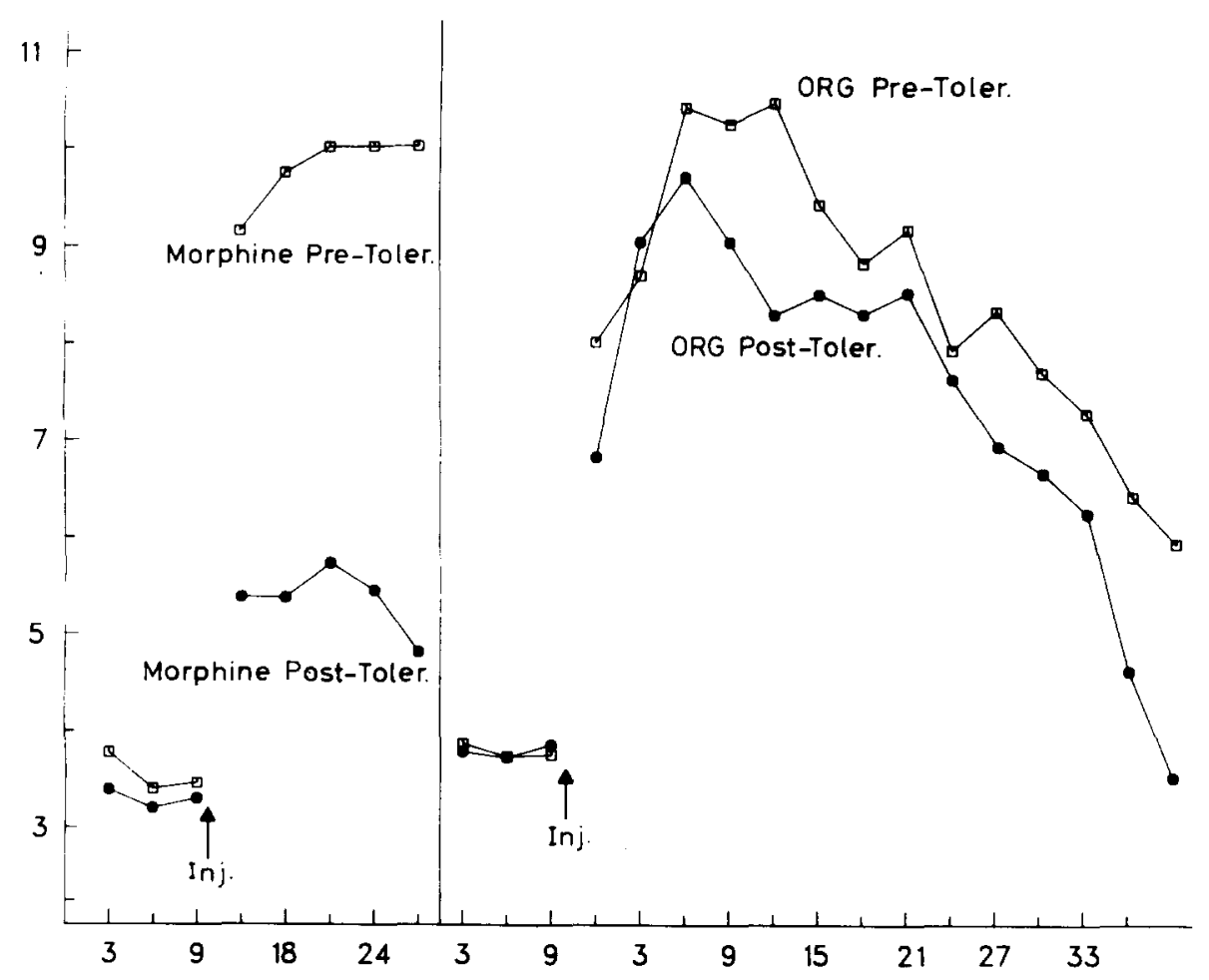

Fig. 4. Mean tail flick latency before and after microinjection of $30 \mu \mathrm{g}$ ORG 2766 or morphine in morphine tolerant or non-tolerant animals. Morphine dose $10.0 \mathrm{mg} / \mathrm{kg}$ i.p. Tolerance was induced by two successive implants of $72 \mathrm{mg}$ morphine pellets. The significant decline of $(P<0.01)$ in the analgesic effects of a single dose of morphine was observed after exposure to the pellets for one week. No signficant effect of morphine tolerance in ORG 2766-induced analgesia was observed. Ordinate: latency (sec); absicssa: time (min).

was $30.5 \pm 7.3$ (S.E.M.) min compared to $33.3 \pm 8.4$ (S.E.M.) min for $30 \mu \mathrm{g}$ alone. How. ever, the small number of subjects make judgements of a small effect of naloxone impossible.

\subsection{Effects of morphine tolerance on anal- gesia produced by $O R G 2766$}

As illustrated in fig. 4, the tolerance regimen produced a marked reduction in the analgesic potency of morphine but not in the potency of ORG 2766. These data were reduced to give a measure of the degree of analgesia as adapted from Harris and Pierson (1964) and were subjected to a 7 (subjects) $X$ 2 (tolerance treatment) $\times 2$ (drug) repeated measures analysis of variance. A significant degree of tolerance was revealed by a main effect $(P<0.01)$, and a significant interaction was observed $\left(\mathrm{F}_{1,6}=4.4, \mathrm{P}<0.05\right)$, indicating the significantly greater effect on morphine analgesia. Furthermore, individual analysis of the effect of morphine before and after the tolerance regimen indicated a significant decline in the effectiveness of morphine $(\mathrm{P}<0.01)$, whereas the same morphine tolerant animals did not exhibit a change in their response to ORG $2766(\mathrm{P}=0.66)$.

\subsection{Opiate binding}

ORG 2766 was not found to displace $\left[{ }^{3} \mathrm{H}\right]$ naloxone from opiate receptors at concentrations up to $10 \mu \mathrm{M}$. Other doses from $1 \mathrm{nM}$ to $10 \mu \mathrm{M}$ were tested. Whereas binding in the presence of $1 \mu \mathrm{M}$ naloxone was only $30 \%$ of total binding, a small increase in binding (4\%) 
was observed with $10 \mu \mathrm{M}$ ORG 2766. Lower doses were equally ineffective.

\section{Discussion}

The results of the present experiments clearly show the effectiveness of the present doses of an ACTH analog in producing analgesia. Informal observations suggested that the ORG 2766 induced true analgesia since animals failed to show escape responses to strong pinches or to pin pricks. The results do not appear to be due to motoric deficits since the animals, while sometimes appearing sedate, often showed normal locomotor activity during the period of profound analgesia. In fact, under the best circumstances analgesia was present in animals which would be difficult or impossible to distinguish from untreated rats on other grounds. The lack of effect of lateral ventricular injections, together with the histological data, strongly suggest that the periventricular gray is the site of action of the ACTH analog.

While the doses used here are considerably higher than are necessary for changes in some behavioral situations, they are comparable to those usually needed for studies of pain sensitivity. For example, ORG 2766 is considerably more powerful than Met-enkephalin, in producing analgesia (Pert et al., 1976; Walker et al., 1977a, b). Using methods similar to those of the present experiments, Pert et al. (1976) microinjected $120 \mu \mathrm{g}$ Metenkephalin into the PAG and recorded tailflick responses. Despite the 6 times higher dose (on a molar basis) of enkephalin, ORG 2766 produces about 14 times the analgesia when calculated as area under the curve. In fact, when equated for molecular weight, the analgesic dose of ORG 2766 is approximately equivalent to that of morphine and many times lower than some partial agonists that are used clinically to relieve pain (Yaksh and Rudy, 1978).

The discrepancy in doses is less surprising when one considers the case of the endor- phins. Like ACTH and ACTH analogs, opiate peptides have been found to produce changes in memory and attention at exceedingly low doses (Kastin et al., 1976; De Wied et al., 1978). It has been suggested that these effects on learned behavior (maze performance, extinction and retention of avoidance behavior) are not mediated by opiate receptors since the effects can be seen with opiateinactive analogs, such as the des-tyrosineendorphins (De Wied et al., 1978). On the other hand, the analgesic effects of the endorphins, which occur at higher doses, are antagonized by naloxone, and thought to be opiate receptor mediated. Since these two effects (on learned behavior and pain sensitivity) occur at widely different doses and exhibit different pharmacological susceptibilities, it is likely that their underlying mechanisms are different as well. A similar situation may exist for ACTH. There may well exist two routes of action for ACTH, one that mediates the effects on learned behavior which is most readily seen at low doses, and a second that is reflected in its effects on pain sensitivity, and becomes apparent at higher doses.

Since $\mathrm{ACTH}_{1-24}$ can induce some effects that are reversible by naloxone (Terenius, 1976; Zimmerman et al., 1973; Gispen et al., 1977) and since it binds, with low affinity, to opiate receptors, it was of particular interest to examine the role of the opiate receptor in the present phenomenon. The lack of effect of naloxone in the behavioral experiments, the failure of morphine tolerance to interfere with the analgesic response to ORG 2766, and the lack of its binding to opiate receptors in vitro strongly suggest that non-opiate mechanisms are responsible for the profound behavioral effects of this analog. One possibility is that ORG 2766 interacts with a postulated ATCH or $\alpha-\mathrm{MSH}$ receptor. A particularly relevant finding in support of this view was that septal uptake of a $\left[{ }^{3} \mathrm{H}\right] \mathrm{ACTH}_{1-9}$ analog is specifically reduced by other ACTH-like substances, notably the 1-24 fragment (Verhoef and Witter, 1977).

Behavioral observations indicated several 
other properties of ORG 2766 including its ability to produce straub tail and vigorous jumping. Similar effects have been reported for $\beta$-END (Walker et al., 1977a) and $\mathrm{ACTH}_{1-24}$ (Jacquet, 1978; Walker et al., 1980). Thus, at the level of the PAG, $\beta$-END and $\alpha-\mathrm{MSH} / \mathrm{ACTH}$-like peptides may produce a similar behavioral profile, suggesting parallel actions - presumably mediated via different receptor mechanisms. These data may thus extend the finding by Watson et al. (1978) and others (Pelletier et al., 1977; Mains et al., 1977) of the coexistence of ACTH and $\beta$-END within neurons, by suggesting that ACTH and $\beta$-END have functional similarities as well.

It is not supposed that all effects of $\beta$-END will be mimicked by ACTH-like substances since there are distinct groups of neurons containing only $\alpha-\mathrm{MSH}$ (Watson and Akil, 1980). Moreover, exogenous administration of $\beta$-END undoubtedly results in significant activation of opiate receptors that normally interact with enkephalin. However, the local activation of neurons in $\beta$-END terminal regions by an $\mathrm{ACTH}$ analog and the concomitant analgesic effect suggests that physiologically $\beta$-END and ACTH may have effects that are functionally similar in nature.

\section{Acknowledgements}

The authors wish to express their gratitude to Brad Berson, Cindy Whittington, Diane Pace and Steve McCormack for their expert technical assistance, and to Carol Criss for typing the manuscript. We thank Endo for donating naloxone, and Organon for providing ORG 2766. This work was supported by NIDA grant No. DA 02265-02.

\section{References}

Akil, H., W. Hewlett, J.D. Barchas and C.H. Li, 1980, Binding of ${ }^{3} \mathrm{H}-\beta$-endorphin to rat brain membranes: characterization of opiate properties and interaction with ACTH, European J. Pharmacol. (in press).

Akil, H., S.J. Watson, S. Sullivan and J.D. Barchas, 1978, Enkephalin-like material in normal human cerebrospinal fluid: measurement and levels, Life Sci. 23, 121.

Coy, D.H., A.J. Kastin, J.M. Walker, R.F. McGivern and C.A. Sandman, 1978, Increased analgesic activities of a fluorinated and a dimeric analogue of [D-Ala-2]-methionine enkephalinamide, Biochem. Biophys. Res. Commun. 83, 977.

D'Amour, F.E. and D.L. Smith, 1941, A method for determining loss of pain sensation, J. Pharmacol. Exp. Ther. 72, 74.

De Groot, J., 1959, The rat forebrain in stereotaxic coordinates, Verh. Kon. Ned. Akad. Wet. 52, 1.

De Wied, D., 1977, Peptides and behavior, Life Sci. 20,195 .

De Wied, D., G.L. Kovács, B. Bohus, J.M. Van Ree and H.M. Greven, 1978, Neuroleptic activity of the Neuropeptide $\beta-\mathrm{LPH}_{62-77}$ ([Destyr] $\gamma$-endorphin; DT $\gamma$ E), European J. Pharmacol. 49, 427.

Elde, R., T. Hökfeldt, O. Johansson and L. Terenius, 1976, Immunohistochemical studies using antibodies to leucine-enkephalin: initial observations on the nervous system of the rat, Neurosci. 1, 349 .

Gispen, W.H., M.E.A. Reith, P. Schotman, V.W. Wiegant, H. Zwiers and D. De Wied, 1977, CNS and ACTH-like peotides: neurochemical response and interaction with opiates, in: Neuropeotide Influences on the Brain and Behavior, eds. L.H. Miller, C.A. Sandman and A.J. Kastin (Raven Press, New York).

Gispen, W.H., Tj.B. Van Wimersma Greidanus, C. Waters-Ezrin, E. Zimmerman, W.A. Krivoy and D. De Wied, 1975, Influence of peptides on reduced response of rats to electric footshock after acute administration of morphine, European J. Pharmacol. 33, 99 .

Harris, L.S. and A.K. Pierson, 1964, Some narcotic antagonists in the benzophan series, J. Pharmacol. Exp. Ther. 143, 141.

Jacquet, Y.F., 1978, Opiate effects after adrenocorticotropin or $\beta$-endorphin in the periaqueductal gray matter of rats, Science 201, 1032.

Kastin, A.J., R.D. Olson, A.V. Schally and D.H. Coy, 1979, CNS effects of peripherally administered brain peptides, Life Sci. 25, 401.

Kastin, A.J., E.L. Scollan, M.G. King, A.V. Schally and L.H. Coy, 1976, Enkephalin and a potent ana$\log$ facilitate maze performance after intraperitoneal administration in rats, Pharmacol. Biochem. Behav. 5, 691.

Mains, R.E., B.A. Eipper and N. Ling, 1977, Common precursor to corticotropins and endorphins, Proc. Nat. Acad. Sci. U.S.A. 74, 3014.

Nakanishi, S., A. Inoue, T. Kita, M. Nakamura, A.C.Y. Chang, S.N. Cohen and S. Numa, 1979, Nucleotide sequence of cloned cDNA for bovine corticotropin- $\beta$-lipotropin precursor, Nature 278, 423. 
Pelletier, G., R. Leclerc, F. Labrie, J. Cote, M. Chretien and M. Lis, 1977, Immunohistochemical localization of $\beta$-lipotropin hormone in the pituitary gland, Endocrinology 100, 770.

Pert, C.B., A. Pert, J. Chang, B. Fong, 1976, [D-Ala ${ }^{2}$ ]Met-enkephalinamide: A poent, long-lasting synthetic pentapeptide analgesic, Science 194, 330.

Roberts, J.C. and E. Herbert, 1977, Characterization of a common precursor to corticotropin and $\beta$-lipotropin: Identification of $\beta$-lipotropin peptides and their arrangement relative to corticotropin in the precursor synthesized in a cell free system, Proc. Nat. Acad. Sci. U.S.A. 74, 5300.

Selby, S.M., ed., 1964, CRC Standard Mathetmatical Tables (CRC Press, Cleveland) p. 14.

Terenius, L., 1976, Somatostatin and ACTH are peptides with partial agonist-like selectivity for opiate receptors, European J. Pharmacol. 38, 211.

Terenius, L., W.H. Gispen and D. De Wied, 1975, ACTH-like peptides and opiate receptors in the rat brain: structure-activity studies, European J. Pharmacol. 33, 395.

Verhoef, J. and A. Witter, 1977, Specific uptake of a behaviorally potent ${ }^{3} \mathrm{H}-\mathrm{ACTH}_{1-9}$ analog in the septal area after intraventricular injection in rats, Brain Res. 117.

Walker, J.M., H. Akil and S.J. Watson, 1980, Evidence for homologous action of pro-opiocortin products, Science (in press).

Walker, J.M., G.G. Berntson, C.A. Sandman, D.H. Coy, A.V. Schally and A.J. Kastin, 1977a, An ana$\log$ of enkephalin having prolonged opiate-like effects in vivo, Science 196, 85.

Walker, J.M., C.A. Sandman, R. McGivern, D.A. Coy and A.J. Kastin, 1977b, Endorphin analogs with potent and long-lasting analgesic effects, Pharmac. Biochem. Beh. 7, 543.

Watson, S.J. and H. Akil, 1980, $\alpha$-MSH in rat brain: occurrence within and outside of $\beta$-endorphin neurons, Brain Res. 192, 217.

Watson, S.J., J.D. Barchas and C.H. Li, 1977, $\beta$-Lipotropin: localization of cells and axons by immunocytochemistry, Proc. Nat. Acad. Sci. U.S.A. 74, 5155.

Watson, S.J., C.W. Richard and J.D. Barchas, 1978, Adrenocorticotropin in rat brain: immunocytochemical localization in cells and axons, Science $200,1180$.

Wiegant, V.M., W.H. Gispen, L. Terenius and D. De Wied, 1977, ACTH-like peptides and morphine: interaction at the level of the CNS, Neuroendocrinology 2,63 .

Yaksh, T.L. and T.A. Rudy, 1978, Narcotic analgesics: CNS sites and mechanisms of action as revealed by intracerebral injection techniques, Pain 4, 299.

Yaksh, T.L., J.C. Yeung and T.A. Rudy, 1976, Systematic examination in the rat of brain sites sensitive to the direct application of morphine: observation of differential effects within the periaqueductal gray, Brain Res. 114, 83.

Zimmerman, E. and W.A. Krivoy, 1973, Antagonism between morphine and the polypeptides ACTH, $\mathrm{ACTH}_{1-24}$, and $\alpha-\mathrm{MSH}$ in the nervous system, in: Drug Effects on Neuroendocrine Regulation, Progress in Brain Res., Vol. 39, eds. E. Zimmerman, W.H. Gispen, B.H. Marks and D. De Wied (NorthHolland, Amsterdam) p. 383. 